\title{
Tédio enquanto circunstância potencializadora de tentativas de suicídio na velhice
}

Maria Cecília de Souza Minayo. Fundação Oswaldo Cruz.

Selena Mesquita de Oliveira Teixeira. Faculdade Integral Diferencial.

José Clerton de Oliveira Martins. Universidade de Fortaleza.

\section{Resumo}

O escopo deste artigo é refletir sobre o tédio enquanto circunstância potencializadora das tentativas de suicídio de um idoso institucionalizado. Para realização da pesquisa foram utilizados dois tipos de instrumento: ficha de identificação pessoal e social do idoso e entrevista semiestruturada. Trata-se de um estudo de caso que analisa qualitativamente o discurso do idoso, tomando como direcionamento os princípios da hermenêutico-dialética. Verificou-se que as tentativas ocorreram associadas principalmente às seguintes circunstâncias: relações sociofamiliares fragilizadas, isolamento social, solidão, tempo de vida tedioso, depressão, uso abusivo do álcool e percepção negativa do envelhecer. Considerando a complexidade dos fatores associados às tentativas de suicídio, entende-se que nenhum fator, por si só, foi determinante para a efetivação das tentativas. Embora sejam várias as circunstâncias que envolveram esses eventos e que são relatadas no artigo, pode-se inferir que o tédio, caracterizado como tempo desprovido de sentido, assumiu lugar de destaque.

Palavras-chave: tédio; suicídio; tentativa de suicídio; idoso.

\begin{abstract}
Boredom while potentializer circumstance of suicide attempts in the elderly. The scope of this article is to reflect about the boredom while potentializer circumstance of suicide attempts of an institutionalized elderly. For the realization of this research were used two types of instrument: personal and social identification form of the elderly and semi-structured interview. This is a case study that analyses qualitatively the discourse of elderly using as guidance the principles of hermeneutical-dialectic. It was found that the attempts occurred associated, mainly, with the following circumstances: fragile social-familiar relationships, social isolation, loneliness, tedious lifetime, depression, abuse of alcohol and negative perception of aging. Considering the complexity of the factors associated to suicide attempts, it is understood that none factor, by itself, is determinative for effectuation of the attempts. Though the circumstances that involved these events might be several, and they are reported in this article, it is possible to infer that the boredom, characterized as meaningless time, assumed prominent place.
\end{abstract}

Keywords: boredom; suicide; suicide attempt; elderly.

\section{Resumen}

El tedio como circunstancia que potencia los intentos de suicidio en la vejez. El alcance de este artículo es reflexionar sobre el tedio como potenciador de los intentos de suicidio de los ancianos institucionalizados. Para llevar a cabo la investigación se utilizaron dos tipos de instrumentos: Formulario de identificación personal y social de las personas mayores y entrevistas semiestructuradas. Se trató de un estudio de caso que analiza cualitativamente el discurso de las personas mayores, teniendo como punto de partida los principios de la hermenéutica dialéctica. Se verificó que los intentos se asociaron principalmente con las siguientes circunstancias: relaciones sociales y familiares frágiles, aislamiento social, soledad, vida tediosa, depresión, abuso de alcohol y percepción negativa del envejecimiento. Teniendo en cuenta la complejidad de los factores asociados a los intentos de suicidio, se entiende que ningún factor, por sí mismo, es crucial para la efectividad de los intentos. Aunque son varias las circunstancias que envuelven este hecho, y que son analizadas en el artículo, se puede inferir que el tedio, caracterizado como tiempo desprovisto de sentido, tiene el lugar principal.

Palabras clave: tedio; suicidio; intento de suicidio; ancianos. 
Neste artigo se apresenta o caso de um idoso, que tentou suicídio por duas vezes. Entre uma multiplicidade de circunstâncias, o tédio aparece como forte potencializador dos eventos aqui narrados.

Por tentativa de suicídio entendem-se os atos realizados por indivíduos que pretendem se matar e cujo desfecho não resulta em óbito (Krug, Dahlberg, Mercy, Zwi, \& Lozano, 2002). Tal ação geralmente está relacionada com a impossibilidade de o indivíduo identificar alternativas viáveis para a solução de seus conflitos e sofrimentos, optando pela morte como resposta. Uma série de fatores está associada com o risco de suicídio, incluindo doenças físicas incapacitantes, enfermidades mentais, abuso de álcool e outras drogas e problemas de ordem familiar e socioeconômicos. No caso das pessoas idosas, a maioria dos estudos mostra a forte associação entre o risco de suicídio e as seguintes condições: presença do isolamento e da depressão em diversos graus, de outros distúrbios psiquiátricos, de doenças degenerativas que causam dependência ou sofrimentos físicos insuportáveis, perda da autonomia e isolamento social (Beeston, 2006; Cavalcante \& Minayo, 2012; Conwell \& Thompson, 2008; Minayo \& Cavalcante, 2010). Nessa perspectiva, a tentativa de suicídio é vista como um fenômeno complexo e multicausal, tendo em sua constituição diversos elementos, incluindo aspectos biológicos, história de vida pessoal, eventos circunstanciais e o contexto socioeconômico no qual a pessoa vive e viveu.

O que é o tédio e por que destacá-lo neste estudo de caso? O tédio é definido por Toohey (2012) como um sentimento de repulsa a tudo e a todos, produzido temporariamente em circunstâncias previsíveis, mas inevitáveis. Como comenta o autor, o tédio também é visto enquanto sintoma sociopsicológico (pois nem a sociologia e nem a psicologia, cada uma por si, podem explicá-lo) comum na sociedade e precisa ser compreendido em toda a sua complexidade. O mesmo ressalta Svendsen (2006), salientando que ainda que se assemelhe a algo comum do cotidiano das pessoas, o tédio produz graves consequências para a sociedade e não apenas para o indivíduo. Eastwood, Frischen, Mark e Smilek (2012), por sua vez, o definem como uma experiência adversa de querer, mas não conseguir, exercer uma atividade gratificante.

Na filosofia, o tédio é descrito como uma condição caracterizada pela percepção da vida e de tudo que a cerca como pesado, tedioso e sem estímulos, mas também como um sofrimento a ser enfrentado. Pois essa "condição" é vista como parte essencial da existência e tem seu lado positivo. Heidegger (1999) escreveu que o tédio é "como névoa silenciosa que desliza para cá e para lá nos abismos da existência e nivela todas as coisas, numa estranha indiferença". Sem estímulo ou foco, o indivíduo é confrontado com o sentimento do vazio e da falta de sentido da existência e com experiências de angústia. Mas, ressalta, "O tédio manifesta o ser em sua totalidade" e pode atuar como uma instância de "espera" (p. 55) para a tomada de decisões importantes na vida.

No mundo da vida são inúmeros os exemplos de pessoas tomadas pelo tédio que se afundam nele sem encontrar o caminho de volta, e de outras que o transformam em força criadora. No sentido negativo, é ilustrativo o caso do ator americano George Sanders, que deixou o seguinte recado antes de se suicidar: "Querido mundo, estou deixando você porque estou entediado". Também o jornalista Hunter Thompson declarou numa carta, antes de se matar, que sentia um insuportável tédio por ter vivido 17 anos além dos 50, e que não via a hora de terminar com tudo na vida.

Sobre o lado transformador do tédio também há exemplos bem conhecidos de pessoas que, reagindo a ele, fizeram importantes contribuições à humanidade. É o caso de Einstein, um estudante entediado que não se sentia desafiado na escola. Esse grande gênio considerava o tédio como o mais elevado estado mental, pois foi a partir de sua vida monótona que teve tempo para criar a teoria da relatividade. Steve Jobs, criador da Apple, também defendia esse sentimento, do qual tirava sua curiosidade e criatividade. Woody Allen, que conta não haver terminado a faculdade porque era muito entediante e que, na vida real, não se diverte com quase nada. No entanto o tédio tem valor criativo na elaboração de seus filmes.

Do ponto de vista da psicologia, o tédio está vinculado às relações do sujeito com o tempo, com problemas de atenção e com distúrbios emocionais. Os vários estudos que se orientam nesse sentido consideram que ele reflete uma forma de subjetivação ligada ao ritmo frenético da sociedade atual, que amplia a solidão, fragiliza as relações afetivas e, sobretudo, produz uma sensação de vazio e de ausência de sentido para existir. O sujeito, em resposta a esse tempo acelerado, "mata o próprio tempo" (Oliveira \& Justo, 2010).

Os estudos atuais da psicologia mostram que o tédio causa alterações no funcionamento do cérebro e está vinculado a problemas de atenção. Os estudos mais atuais que se conhecem nesse sentido são as pesquisas de Eastwood et al. (2012), que trabalhando em estreita 
colaboração com a neurociência, definiram o tédio como um "estado aversivo" que ocorre quando (a) a pessoa não é capaz de orientar sua atenção para informações internas (pensamentos e sentimentos) e externas (estímulos do ambiente), requeridas para participar de atividades que lhe deem satisfação; (b) quando o indivíduo não é capaz de dar atenção e de participar de atividades que o satisfaçam; (c) quando atribui a causa de seu estado aversivo ao ambiente que o cerca.

A maioria dos estudos de psicologia enfatiza também o sofrimento emocional da pessoa entediada diante de um tempo que parece não ter fim ou o "vazio do tempo frente ao vazio de significado" (Svendsen, 2006 , p. 32). Esse autor compara o tédio que invade o sujeito com a sutileza de uma poeira. Ele pode levar a mudanças positivas, mas muitos não resistem ao fastio e à péssima sensação de um tempo intolerável. Nesses casos, o tédio direciona o indivíduo para o desespero ou para a desesperança (Matos, 2012).

Na perspectiva de focalizar o tédio com os vários aspectos assinalados, apresenta-se o caso de Raimundo nome fictício da pessoa idosa -, cuja história e circunstâncias de vida o conduziram a repetir por duas vezes tentativas de suicídio. Seu caso engloba a sensação do vazio do tempo e a falta de perspectiva de que algo possa mudar em sua vida. Assim essa história se enquadra no que Svendsen (2006) denomina "morte em vida" (p. 42), em que a pessoa permanece viva, mas não encontra forças para sair da situação de sofrimento, "numa espécie de antecipação pálida da morte" (p. 42).

Nesse contexto, o risco de suicídio se amplia, pois o tédio, sobretudo quando aliado à depressão, não se afigura como uma situação passageira, e sim como uma orientação existencial que considera a morte o único caminho para a solução do intenso sofrimento marcado pelo tempo desprovido de sentido (Parente, Soares, Araújo, Cavalcante, \& Monteiro, 2007). Se, em geral, as tentativas de suicídio de uma pessoa idosa ocorrem associadas a vários fatores, o tédio potencializa esse infindável sofrimento psiquico.

\section{Percurso metodológico}

Este artigo narra o caso de uma pessoa idosa residente na cidade de Teresina ( $\mathrm{PI}$ ) que realizou duas tentativas de suicídio. É-lhe atribuído o nome fictício de Raimundo. A seleção desse caso obedeceu ao seguinte critério: pessoa com 60 anos ou mais no período em que havia tentado suicídio. Como critério de exclusão estabeleceu-se que o idoso não deveria ter dificuldades mentais para se expressar e narrar sua história e nem estar em crise no momento da entrevista.

Para se chegar a Raimundo, fez-se um levantamento de casos de tentativas de suicídio na cidade de Teresina, a partir do contato com profissionais de saúde mental e agentes comunitários de saúde, considerando-se que esses profissionais teriam informações sobre os possíveis participantes da pesquisa. A investigação privilegiou a perspectiva da pessoa selecionada sobre todas as questões e problemas narrados por ela, enfatizando o ato de tentativa de suicídio e as circunstâncias que o envolveram.

A entrevista com Raimundo se iniciou com a leitura e assinatura do Termo de Consentimento Livre e Esclarecido. Em seguida, foi preenchida uma ficha para sua identificação, incluindo informações de ordem pessoal, sociocultural e familiar. Após o cumprimento dessas etapas, teve início a realização da entrevista semiestruturada, com base no Roteiro de Entrevista Psicossocial, padronizado por Minayo, Cavalcante, Figueiredo e Mangas (2013). No entanto, esse roteiro foi apenas orientador, pois não se obedeceu a uma ordem fechada das questões. Ao contrário, a interlocução com Raimundo esteve atenta à compreensão de seu estado emocional e balizou-se no respeito às relevâncias apontadas por ele. A entrevista foi realizada num local de sua preferência, de modo que ficasse à vontade para expressar-se em seu relato, e ocorreu por meio de várias conversas e sem tempo pré-determinado para ser concluída. A fala do idoso foi gravada com seu consentimento e posteriormente transcrita na íntegra.

A análise qualitativa da entrevista foi guiada pelos princípios da hermenêutico-dialética, que busca compreender a fala dos sujeitos no seu contexto e dentro de sua própria lógica. E também levou em consideração as condições sociais, culturais, institucionais, de poder e de personalidade que influem nas contradições de sua narrativa (Azevedo, 2004; Minayo, 2002). Tomando-se como direção os objetivos propostos na investigação, optou-se por discutir o referido caso mediante a compilação das falas emblemáticas organizadas em categorias, realizando-se, em seguida, seu balizamento com a literatura sobre tentativas de suicídio e seus fatores associados, com ênfase nos sintomas do tédio.

Para este estudo se utilizaram os mesmos instrumentos e estratégias de abordagem desenvolvidas por Minayo et al. (2013) num estudo multicêntrico de âmbito nacional sobre tentativas de suicídio de idosos no Brasil. A referida pesquisa foi aprovada pelo Comitê de Ética em Pesquisa da Fundação Oswaldo Cruz (CEP/ FIOCRUZ). 


\section{Resultados e discussão}

\section{Descrição da Situação: o Gesto Suicida Fala mais da Vida que da Morte. A História de Vida}

Para se falar sobre a vida de uma pessoa idosa é importante compreender sua história, seu passado, seu presente e perspectiva de futuro (Lima, 2008). Como lembra Peixeiro (2010), "os aspectos culturais e a constituição de cada sujeito concorrem para direcionar a maneira como cada um vai atravessar, na velhice, esse momento de confrontação das perdas" (p. 77). Aqui se colocam alguns fragmentos da história de Raimundo, cujo passado de sofrimento e precárias condições de vida se projetam no presente sem deixar uma janela aberta ao futuro, a não ser sua vontade de morrer.

Raimundo atualmente reside numa Casa de Repouso e foi diagnosticado com depressão por duas profissionais da saúde que lhe prestam assistência no local. O diagnóstico a ele atribuído, somado à recorrente desmotivação para viver, está associado a duas tentativas de suicídio.

$\mathrm{Na}$ entrevista, Raimundo contou que é viúvo, tem 69 anos, cor parda, é católico não praticante e é natural da cidade de Teresina. Nunca frequentou escola e não aprendeu a ler e escrever. Reside, desde 2007, nessa Casa de Repouso, mantida pelo Governo do Estado do Piauí. Não exerce qualquer atividade e não mantém contato com nenhum familiar há mais de uma década. Foi casado durante quatro anos, mas a esposa morreu. Denominada ficticiamente de Ana, nunca trabalhou fora de casa, dedicando-se apenas aos serviços domésticos. 0 casal teve somente um filho, que morreu aos 19 anos em acidente de carro. Raimundo comentou que tem uma filha não biológica que the foi dada por um parente distante. Ele ajudou a criá-la e a educá-la, mas perdeu seu contato e ela não o procura. Quando Ana era viva, o casal residia em uma humilde casa própria, de taipa, com apenas dois cômodos e um banheiro externo feito de palha.

Raimundo contou que trabalhou a maior parte de sua vida como vendedor de ferro velho. Juntava e comprava objetos não mais utilizados e os revendia. Sentia-se bem com sua ocupação e a considerava importante, pois, por meio dela, mantinha o sustento de sua casa. Depois da morte de Ana e do filho, Raimundo perdeu totalmente o contato com outras pessoas da família e passou a viver nas ruas. Deixou de trabalhar e sobrevivia daquilo que recebia de outras pessoas. Costumava pedir água e comida nas residências. Tomava banho nos rios da cidade e dormia sobre um papelão, numa calçada.

Após muitos anos vivendo sem um teto, Raimundo buscou abrigo na Casa de Repouso, para ter um local onde dormir, tomar banho e alimentar-se. A partir de então passou a ser mantido apenas pelas verbas que o governo do estado destina à Casa de Repouso. Considera que as pessoas que cuidam dele o tratam bem e preza particularmente o fato de poder se alimentar em todos os horários de refeição. No decorrer das conversas, Raimundo contou que apesar dos cuidados que recebe se sente muito sozinho, pois não tem com quem conversar ou aonde ir. Há cinco anos ficou cego, e desde então sai pouco do quarto. Ressaltou que não tem quem o leve para passear ou caminhar e não tem autonomia para ir e vir, por conta da deficiência visual. Vive em seu aposento esperando as horas passarem, esperando a morte chegar.

"Eu desejei morrer muitas vezes". Raimundo tentou findar a própria vida pela primeira vez antes dos 60 anos. Comentou que, nessa ocasião, estava sofrendo muito com o desprezo da família e com a solidão que sentia. No dia em que tentou se matar, saiu de manhã para beber em um bar. Enquanto se embriagava, recordava-se dos momentos em que se sentiu rejeitado pelos familiares e teve muita raiva. No caminho de volta para casa decidiu dar cabo à vida. Já na residência, pegou uma faca e começou a cortar os próprios pulsos. Estava sozinho, mas foi encontrado ainda com vida pelos vizinhos, que o ajudaram e o conduziram ao hospital mais próximo.

Raimundo contou que antes da primeira tentativa pensava com frequência em como poderia concretizar o suicídio, e que sempre que estava em crise, alimentava desejos de morte. Entretanto, no dia em que cortou os pulsos não havia planejado fazê-lo. E considera que tenha sido impulsionado pela embriaguez. Relatou que quando jovem e na vida adulta já fazia uso abusivo de álcool e reconhece o quanto essa dependência o prejudicou. Pontuou que sempre que bebia ficava agressivo e tomava atitudes impensadas, como a que o levou a tentar suicídio.

A segunda tentativa ocorreu quando Raimundo, com mais de 60 anos, já se encontrava institucionalizado. Segundo ele, seu ato foi motivado principalmente pela solidão, pela sensação de impotência frente à deficiência visual ocasionada pelo diabetes, a ausência da família, o isolamento e por não ver sentido na vida. Para consumar o suicídio, tentou pular de uma grade próxima ao quarto, crendo que houvesse altura adequada para que a queda 
ocasionasse sua morte. Mas o salto não foi suficiente para tirar-lhe a vida: foi encontrado pelos cuidadores da Casa de Repouso ainda no local do ato.

Raimundo não recorda precisamente quando as tentativas ocorreram e argumenta que é muito difícil controlar o tempo (um tempo infindável!) quando se vive apenas dentro de um quarto sem nada fazer, sobretudo sem enxergar. Ressaltou que nessas condições os dias parecem todos iguais.

"Eu senti um aperto muito forte no coração". Antes de tentar suicídio pela primeira vez, Raimundo relatou que se sentia muito triste e revoltado com a vida. Detalhou a raiva que o possuía quando cortou os pulsos, lembrando o desprezo e a rejeição que sofreu da família, após a viuvez. Nas duas tentativas, disse que estava deprimido e sem paciência para esperar uma possível melhora. Mencionou ter sentido uma grande tristeza, como "um aperto muito forte no coração". Os pensamentos suicidas lhe acompanhavam a dor emocional intensa. E provocar a própria morte lhe pareceu a única saída possível para acabar de vez com o sofrimento.

Nos dois momentos em que tentou tirar a própria vida, Raimundo apresentava sinais de lucidez e clareza em relação às consequências de seu ato. Havia uma intenção real de morte, bem como a noção de que o desfecho poderia ser fatal. Relatou que foi atendido por um psiquiatra há uns 10 anos, e que o profissional não Ihe receitou qualquer medicação. Apenas o aconselhou a "tentar não pensar em nada, pois não devia ficar se lembrando dos acontecimentos ruins que tinham acontecido na sua vida". Atualmente, Raimundo faz uso de medicamento contra depressão e tem acompanhamento psicológico oferecido pela própria Casa de Repouso. Nunca utilizou os serviços dos Centros de Atenção Psicossocial (CAPS) e nunca ouviu falar sobre eles.

Por ocasião das duas tentativas, Raimundo não demorou em receber os devidos cuidados. A primeira foi considerada pelos médicos como de alta gravidade, por ter sido utilizado um método muito violento. Por causa do sangramento, ele teve que ficar internado e recebeu cuidados num hospital. Um importante critério de avaliação da intencionalidade, defendido pela literatura, é o que compreende a potencialidade do método de perpetração de provocar a morte e a consciência da irreversibilidade do ato. $\mathrm{O}$ grau de letalidade indica o grau de intencionalidade, além de possibilitar a avaliação do nível de dor psíquica que a vítima experimentou. Outros fatores assinalados na literatura que se associam à seriedade do ato praticado por Raimundo são: ser homem; alimentar desejos de morte; tentar matar-se enquanto estava sozinho; já ter ameaçado tirar a vida antes; e ter traços de personalidade impulsivos e agressivos (Werlang, Macedo, \& Asnis, 2005).

A segunda tentativa foi considerada de gravidade moderada, por envolver ideação suicida e um plano geral. No entanto, o modo de perpetração escolhido, a queda de altura insuficiente para provocar a morte - cuja falha pode ser explicada pela sua cegueira - não lhe resultou em grandes consequências físicas. Após esse episódio, a equipe de cuidadores da Casa de Repouso retirou do quarto de Raimundo alguns objetos que poderiam ser utilizados na concretização de suicídio, conforme propõem a Organização Mundial de Saúde (Krug et al., 2002) e outros autores, como Conwell e Thompson (2008).

"A fé me ajuda, mas a tristeza e a vontade de morrer não passam". Raimundo enfatizou, em seu depoimento, que atualmente se sente arrependido das tentativas de suicídio que efetivou. Mencionou que os atos por ele praticados apenas aumentaram a vergonha que seus parentes já sentiam em relação à forma como levava a vida, reafirmando que havia uma relação conflituosa entre eles. A família passou a desprezá-lo ainda mais e se afastou dele totalmente. Nunca mais procurou saber de seu estado de saúde. Não se encontrou registro de ligações ou de visitas recebidas depois de ambas as tentativas. Entretanto, os familiares foram informados sobre sua situação tanto pela equipe do Hospital (depois do primeiro evento) como pelos profissionais da Casa de Repouso (após o segundo).

O idoso enfatiza que atualmente busca apoio na fé para enfrentar sua persistente tristeza. Apesar de não participar de nenhum grupo religioso, afirma ser católico, acreditar em Deus e recorrer aos santos da igreja quando os "pensamentos ruins" aparecem. Contudo, comenta que quando a tristeza é muito forte não consegue encontrar apoio em Deus. E em consequência, julga ter feito algo muito ruim para merecer tanto sofrimento.

Nesse momento da vida, Raimundo não considera nada importante nem em relação a si próprio nem a tudo que o cerca. Sua carência afetiva é patente: relata que não recebe carinho de ninguém e que nunca recebeu cuidados e amor de qualquer pessoa em sua vida. É importante destacar que num momento anterior da entrevista havia dito que é bem tratado dentro da instituição, separando assim o reconhecimento pelos serviços que recebe da relação amorosa que lhe faz falta. 


\section{Circunstâncias Potencializadoras do Suicídio}

Os principais fatores predisponentes a tentativas de suicídio serão aqui descritos e analisados a partir do caso de Raimundo: (1) tédio; (2) problemas e conflitos familiares; (3) ideações e tentativas prévias; (4) transtornos psicológicos; e (5) cegueira associada ao diabetes.

Tédio como "tempo de morte em vida". No caso de Raimundo é importante enfatizar a propensão para o tédio (Watt \& Vodanovich, 1999) e sua presença (Svendsen, 2006) como circunstâncias de risco. Em sua história, esse sintoma emerge e ressalta seus diferentes aspectos negativos tratados por vários autores: uma relação problemática com o tempo; a existência empobrecida de sentidos; o desinteresse e a falta de atenção pelo que acontece no mundo e apatia frente à vida; e um vazio emocional profundo (Eastwood et al. 2012; Oliveira \& Justo, 2010; Svendsen, 2006; Toohey, 2012), traços que podem ser constatados nos fragmentos de fala a seguir:

Está com muito tempo em minha vida que eu não faço nada. Eu tenho muitos anos que não saio desse quarto. Uma vida dessas é muito dolorosa e devagar. Fico abatido por isso. O tempo eu não ocupo não, eu não trabalho, tudo que eu preciso para continuar vivo vem aqui para dentro desse quarto, comida e água. Eu fico parado só esperando a hora passar. Passo o dia inteiro deitado nessa rede esperando o tempo passar, só levanto mesmo para fazer xixi nesse penico e para comer quando a moça traz. Eu não tenho nenhuma alegria nessa vida. Nem enxergar mais as coisas eu posso. E depois que eu fiquei velho, aí tudo ficou pior. Sou uma pessoa triste e sozinha, não tenho vontade alguma de viver. Uma vida assim não tem sentido, não tem valor para nada.

O tédio como "tempo de morte em vida" (Svendsen, 2006) pode ser exemplificado na história de Raimundo quando ele fala de "tempo sem nada para fazer"; "tristeza sem fim numa vida sem sentido"; "sentimento de inutilidade"; e "sensação de que nada importa mais no mundo". Seu tédio se apresenta como uma forma de descartar a própria história como "tempo vivido de mal-estar com o qual não sabe o que fazer" (Matos, 2012, p. 55). Assim, sua insatisfação insidiosa transcorre lentamente e independe de sua vontade (Buchianeri, 2012), assemelhando-se a um aprisionamento doloroso do qual, pensa, apenas a morte o livrará.

Embora, conforme assinala Heidegger (1999), o tédio possa se transformar numa extraordinária força criadora, esse não é o caso de Raimundo. É exatamente a falta de sentido que o conduz ao tédio, ou, como num efeito recursivo, o tédio o leva à falta de sentido, de modo que ele vai perdendo o referencial de si mesmo, tornando-se igual a tudo em seu entorno.

Considerando a vivência de Raimundo, faz-se necessário pontuar que a sensação de estar entediado pode ser potencializada em situações de institucionalização, pois, em geral, mesmo contrariando a vontade do idoso, sua liberdade volitiva é retirada, sobretudo frente à necessidade de adaptação às normas da Instituição. Desse modo, arbitrariamente o idoso deixa de responder por si mesmo, fragilizando-se (Coudin \& Alexopoulos, 2010).

Para o idoso institucionalizado, algumas questões, como a rotina rígida, ficam em evidência, e assemeIham-se a um fardo para grande parte dos internos. Nesse sentido, identifica-se uma desaceleração do tempo, que muitas vezes é controlado de tal modo que parece passar em câmera lenta. Apesar de a noção do tempo vivido dentro da Instituição de Longa Permanência ser algo específico que parte da subjetividade, sabe-se que há uma predominância em relação a sua lentificação e congelamento (Faleiros \& Morano, 2009). Tal problemática gerou enfado no idoso, intensificado pela monotonia decorrente da homogeneização, isto é, pela mesmice da rotina e o estabelecimento de regras que padronizam os modos de vida do interior da instituição.

Laços familiares frouxos e conflituosos. Raimundo relatou que perdeu os laços com a mulher, o filho, e depois com sua própria casa; foi para a rua e deixou de trabalhar. Casa e trabalho são elementos essenciais de constituição dos sujeitos. Buchianeri (2012) comenta que as vivências dos indivíduos se refletem na forma como organizam seu mundo interior e exterior. Ele já vivia se isolando antes de ficar cego e assim permanece à espera do fim. Tais circunstâncias são conhecidas como de risco para tentativas de suicídio e suicídio consumado: morte da esposa, perda do filho em situação de violência, relações familiares fragilizadas (Cavalcante \& Minayo, 2012; Conwell \& Thompson, 2008; Meneghel et al., 2012; Minayo \& Cavalcante, 2010). Observou-se a quase inexistência de vínculos familiares e sociais, tendo como consequência a solidão e o isolamento social do idoso. É o que se pode notar nos fragmentos de falas a seguir.

Minha vida mesmo foi só sofrimento. Primeiro eu perdi meus pais, que eram os únicos que se importavam comigo. Depois que eles morreram, as outras pessoas da minha família passaram a me desprezar, a ter vergonha de mim. Depois em outro tempo morreu minha mulher e meu filho, aí eu fiquei sem 
ninguém mesmo. Minhas irmãs tinham desprezo forte pela minha pessoa. Era mesmo uma desunião. Minha família me abandonou há muitos anos, não manda nada para mim, nunca ninguém me visitou.

Vários autores (Cavalcante \& Minayo, 2012; Figueiredo et al., 2012) que trabalham com a questão do suicídio ressaltam que a família é um suporte basilar para o sujeito, e quando funcional, é percebida como uma força protetora. Porém, a desunião e os conflitos familiares podem ampliar o risco de suicídio de seus membros quando outros fatores predisponentes estão envolvidos, como mostra a história de Raimundo, repleta de conflitos, sensação de desprezo e rejeição por parte dos parentes.

Ideações e tentativas prévias. Outro fator bastante reconhecido nos estudos nacionais (Cavalcante \& Minayo, 2012; Minayo \& Cavalcante, 2010) e internacionais (Beautrais, 2001; Conwell \& Thompson, 2008; Conwell, Duberstein, \& Caine, 2002) são as tentativas prévias e as ideações persistentes, o que aparece claramente na história de vida de Raimundo. Ideação se configura como um pensamento persistente que induz e incita ao suicídio. Por tentativa se entende uma ação voltada para tirar a própria vida que não resulta em óbito.

Eu ficava pensando antes como é que eu podia fazer, porque a vontade já tinha vindo outras vezes, mas nesse dia eu fiz, cortei os pulsos. Não avisei que ia fazer naquele dia, mas falei pra algumas pessoas que queria morrer. Eu falava sempre, acho que não faziam era acreditar. Meu tempo é assim, sem nada, eu também perdi o gosto de tudo, tudo, tudo, perdi o gosto de viver e só fico pensando no fim. Depois que eu fiquei velho já me senti muitas vezes sem querer mais viver.

A presença de ideação suicida e de tentativas prévias de suicídio eleva o risco da morte autoinfligida (Ministério da Saúde, 2006). Como se pode observar, Raimundo expressou suas intenções de acabar com a vida, mostrando culpa, desalento e menos-valia.

Transtornos mentais. Segundo o Ministério da Saúde (2006), o comportamento suicida é mais comum quando alguns problemas mentais e de certas condições clínicas tornam a pessoa vulnerável, como no caso da depressão, dos transtornos de personalidade e da dependência de álcool ou de outras substâncias psicoativas. Raimundo foi diagnosticado com depressão por duas profissionais de saúde mental que o acompanham. A depressão na velhice é frequentemente impulsionada pelo luto antecipado em relação ao fim da própria vida
(Goldfarb, 2004). A impossibilidade da realização concreta desse luto direciona o sujeito para um desligamento e uma desmotivação profunda quanto à vida, ocasionando um desinvestimento do idoso em relação a si mesmo.

Segundo Gotter (2010), a depressão é considerada uma das mais presentes formas de mal-estar contemporâneo entre idosos, estando diretamente vinculada ao significativo aumento do número de suicídios entre eles. Esse transtorno se afigura em diferentes graus de importância como mostram Mitty e Flores (2008) e Cavalcante, Minayo e Mangas (2013) numa análise sobre suicídio de pessoas idosas: ela pode se mostrar como um estado depressivo provocado por vários problemas da vida ou chegar a ser uma patologia de extrema gravidade. Seus sintomas mais comuns são transtorno de humor, perda de interesse, de energia e de prazer pela vida; tristeza profunda, negatividade, desesperança e pensamentos sobre a morte. É o fator de risco para o suicídio mais relevante, segundo a literatura. Na história de Raimundo apresenta-se associado a abandono; solidão; vida tediosa; conflitos familiares; tristeza e negatividade profunda; percepção estigmatizada do envelhecer. Esses sinais podem ser observados nos seguintes fragmentos de fala:

\begin{abstract}
Eu não sirvo para nada. Sou um velho que está só esperando minha hora chegar. Mas é Deus quem sabe! Só me resta esperar. Acho que viver assim é minha sina. É ficar do jeito que está mesmo, agora é só esperar. Na minha situação só dá jeito a morte, um dia ela chega. Ninguém dá valor para gente velha não. Pode ver o tanto de velho abandonado nesse lugar, porque a família não quer nem saber. E quando a gente fica velho não tem mais saúde nem vontade de fazer nada. Eu me sinto muito deprimido. Elas trazem uns remédios para mim, mas eu não sei para que eles servem.
\end{abstract}

A depressão costuma ser acompanhada por sintomas somáticos, como cansaço, alterações no sono e no apetite. Vários autores pontuam que diante da consciência da proximidade da morte há um declínio corporal, bem como uma redução na maioria dos estímulos da vida, incluindo fragilidade emocional e sentimento de perda do valor social. Esses fatores contribuem para a ampliação do sofrimento psíquico do idoso e para várias formas de depressão (Hornstein, 2006). Em Raimundo nota-se a falta de força interior para sair da situação em que está, o que o leva a concluir: "eu não valho nada". Para esse idoso, os sentimentos depressivos são potencializados pela condição clínica provocada pelo diabetes, que lhe causou a perda da visão. 
Doenças físicas e degenerativas. Essas doenças constituem circunstâncias associadas ao suicídio quando outros fatores estão presentes (Cavalcante \& Minayo, 2012). Enfermidades incuráveis ampliam a dor do sujeito, especialmente quando somadas a uma condição incapacitante ou limitante, o que se pode observar nos seguintes fragmentos de fala.

Depois que fiquei cego, que já tem cinco anos, eu quase nunca saí desse quarto. Não tenho quem me leve para passear ou caminhar aí fora. Eu não posso sair sozinho pra não cair, então fico só aqui dentro mesmo, só parado. Depois que perdi a visão também perdi o gosto de tudo, tudo, tudo, perdi o gosto de viver. A cachaça me atrapalhou muito, eu ficava ruim dos nervos e sem pensar. Quando eu era jovem eu bebia e ficava era valente.

Em Raimundo, a cegueira em si está associada a um grave diabetes que progressivamente o foi debilitando. Outra circunstância de risco, aqui, é o uso abusivo de álcool, que funciona como potencializador do comportamento suicida, sendo ao mesmo tempo consequência e causa da hostilidade e dos impulsos que conduzem ao autoextermínio. Estudos de Sher (2006) revelam que alcoolistas têm 60 a 120 vezes maior probabilidade de tentar suicídio do que quem não faz uso abusivo dessa substância. $\mathrm{O}$ abuso de álcool se caracteriza, pois, como um potente fator precipitante do comportamento autodestrutivo, sempre associado a outras circunstâncias que, como se sabe, são causadas e causadoras.

\section{Conclusão}

A análise do caso de Raimundo mostra que o tédio, o isolamento social, a rejeição da família, o abuso de álcool e a presença da cegueira e da depressão são circunstâncias que, associadas, contribuíram para suas tentativas de suicídio e uma persistente ideação de dar cabo à vida, mesmo quando protegido numa instituição que lhe oferece a satisfação das necessidades básicas. $O$ tédio aparece associado à depressão, como o sintoma de um tempo não preenchido e vazio, uma desatenção perene com tudo que o possa vinculá-lo interior e exteriormente à vida institucional, comunitária e social.

Tratando-se do caso investigado, pode-se inferir que grande parte dos sofrimentos descritos pelo idoso relacionava-se a conflitos de ordem familiar e à sensação de desprezo e rejeição resultante desses conflitos, além de a uma vida tediosa. A desmotivação e a falta de sentido em manter-se vivo ancoravam-se especialmente nessas questões.

À luz da fenomenologia do tédio em Heidegger, compreende-se tal fenômeno como uma forma de ser e estar no mundo. Para o filósofo, o tédio se dá a partir da confluência do homem com o mundo, desvelando o modo como o sujeito se posiciona diante da vida. O cotidiano de Raimundo ilustrou uma vida tediosa que se caracteriza por ser tíbia, insípida, vazia, sem sentido, infeliz, sombria, intolerável (La Taille, 2009), feita de momentos que demoram a passar e da sensação de que nada mais vale a pena ser feito.

Nessa condição o tédio foi perpassado por experiências de rejeição, solidão e exclusão social, em que o idoso posicionava-se de forma estagnada frente à continuação da própria vida. Assim, entende-se que o entediado deixa de ser artesão de si, pois para de refletir sobre o mundo em que vive e sobre sua atuação nesse mundo. Os discursos do idoso revelaram o tédio como fator que mais obscureceu sua percepção de novas possibilidades de transpor a intenção suicida.

Tratando-se da história investigada, pode-se inferir que a institucionalização potencializou o sofrimento do idoso em questão, especialmente, pela escassez de afeto mediante a assistência recebida na Instituição de Longa Permanência. $O$ ato de cuidar não compreende apenas o atendimento às necessidades básicas de cada ser humano, pois requer, sobretudo, uma postura de acolhimento do cuidador. Nesse contexto, Raimundo enfatizou que recebeu apenas os cuidados essenciais para manter-se vivo e uma assistência automatizada, sentindo-se, por isso, abandonado e negligenciado.

O acolhimento dos cuidadores constitui também a rede de apoio informal para os idosos, que necessitam de um ambiente confortável para o seu bem-estar, no qual possam estabelecer e manter laços afetivos consistentes, promotor da sensação de pertencimento e da sua proteção. Quando o idoso recebe esse suporte afetivo e humanizado tende a ter menos dificuldades para lidar com o estresse e superar os obstáculos do cotidiano. Vale frisar que viver em um ambiente facilitador recebendo suporte afetivo dos cuidadores aproxima o idoso da possibilidade de uma velhice digna e com qualidade.

O desejo de morte e sua proximidade sempre dizem menos sobre esses momentos de dor e tristeza e muito mais sobre a vida da pessoa, seus afetos e rupturas, seus anseios não realizados e o caminho no qual, mesmo frente a poucas possibilidades, a pessoa 
imprime a sua existência. Nesse sentido, a história de Raimundo reafirma a definição de que o suicídio é um ato voluntário - e não uma determinação externa - frente a um sofrimento insuportável. Desse modo, conhecer o fenômeno sob a perspectiva do próprio idoso que tentou antecipar a sua morte possibilita compreendê-lo em profundidade, considerando, sobretudo, as peculiaridades do caso analisado.

Porém, se são os eventos da vida (isolamento, transtornos mentais, dramas familiares, doenças degenerativas, dentre outros) que orientam a pessoa para a morte autoinfligida, muito ainda há que ser feito no que tange a pesquisas e ações preventivas, pelas famílias, pelo sistema de saúde e pela sociedade em geral, haja vista tratar-se de evento complexo e de causas múltiplas.

\section{Referências}

Azevedo, M. A. (2004). Informação e interpretação: uma leitura teórico-metodológica. Perspectivas em Ciências da Informação, 9(2), 122-133. Recuperado de http://portaldeperiodicos.eci.ufmg.br/index. php/pci/article/view/354

Beautrais, A. L. (2001). Suicides and serious suicide attempts: two populations or one? Psychological Medicine, 31(5), 837-845. doi: $10.1017 /$ S0033291701003889

Beeston, D. (2006). Older people and suicide. Staffordshire University. Recuperado de www.staffs.ac.uk/staff/profiles/db4.jsp

Buchianeri, L. G. C. (2012). Velocidade e tédio: o paradoxo da adolescência no mundo contemporâneo (Tese de doutorado). Faculdade de Ciências e Letras [UNESP], São Paulo, São Paulo. Recuperado de http://acervodigital.unesp.br/handle/unesp/167662

Cavalcante, F. G., \& Minayo, M. C. S. (2012). Autópsias psicológicas e psicossociais de idosos que morreram por suicídio no Brasil. Revista Ciência \& Saúde Coletiva, 17(8), 1945-1954. doi: 10.1590/S141381232012000800002

Cavalcante, F. G., Minayo, M. C.S, \& Mangas, R. M.N. (2013). Diferentes faces da depressão no suicídio em idosos. Ciência \& Saúde Coletiva, 18(10). doi: 10.1590/S1413-81232013001000023

Conwell, Y., \& Thompson, C. (2008). Suicidal behavior in elders. The Psychiatric clinics of North America, 31(2), 333-356. doi: 10.1016\%2Fj. psc.2008.01.004

Conwell, Y., Duberstein, P. R., \& Caine, E. D. (2002). Risk factors for suicide in later life. Biological Psychiatry, 52, 193-204. doi: 10.1016/ S0006-3223(02)01347-1

Coudin, G., \& Alexopoulos, T. (2010). Help me! I'm old! How negative aging stereotypes create dependency among older adults. Aging \& Mental Health, 14(5), 516-523. doi: 10.1080/13607861003713182

Eastwood, J. D., Frischen, A., Mark, J. F., \& Smilek, D. (2012). The unengaged mind: defining boredom in terms of attention. Perspectives on Psychological Science, 7(5), 482-495. doi: $10.1177 / 1745691612456044$

Faleiros, V. P., \& Morano, T. (2009). Cotidiano e relações de poder numa instituição de longa permanência para pessoas idosas. Textos \& Contextos, 8(2), 319-338. Recuperado de http://revistaseletronicas. pucrs.br/ojs/index.php/fass/article/view/6347/4646
Figueiredo, A. E. B., Silva, R. M., Mangas, R. M. N., Vieira, L. J. E. S., Furtado, H. M. J., Gutierrez, D. M. D., \& Souza, G. S. (2012). Impacto do suicídio da pessoa idosa em suas famílias. Ciência \& Saúde Coletiva, 17(8), 1993-2002. doi: 10.1590/S1413-81232012000800010

Goldfarb, D. C. (2004). Demências. São Paulo: Casa do Psicólogo.

Gotter, M. E. M. (2010). A manifestação de episódios depressivos na velhice: o corpo, as ideias hipocondríacas e o desamparo. São Paulo. Recuperado de http://geracoes.org.br/novo_site/wp-content/ uploads/2013/08/A-manifestacao-de-episodios-depressivos-na-velhice-o-corpo-as-ideias-hipocondriacas-e-o-desamparo.pdf

Heidegger, M. (1999). Conferências e escritos filosóficos. São Paulo: Nova Cultura.

Hornstein, L. (2006). Depresiones: del Reduccionismo a la Complejidad. Buenos Aires: Editorial Paidós.

Krug, E. G., Dahlberg, L. L., Mercy, J. A., Zwi, A. B., \& Lozano, R. (Orgs.). (2002). Relatório mundial sobre violência e saúde. Genebra: OMS.

La Taille, Y. (2009). Formação ética: do tédio ao respeito de si. Porto Alegre: Artmed.

Lima, P. M. R. (2008). A arte de envelhecer: um estudo sobre história de vida e envelhecimento (Dissertação de mestrado). Universidade de Brasília, DF. Recuperado de http://www.openthesis.org/documents/ arte-de-envelhecer-um-estudo-302213.html

Matos, O. (2012). Educação para o ócio: da acídia à preguiça heroica. In A. Novaes (Org.), Mutações: elogio à preguiça (pp. 385-404). São Paulo: Edições SESC.

Meneghel, S. N., Gutierrez, D. M. D., Silva, R. M., Grubits, S., Hesler, L. Z., \& Ceccon, R. F. (2012). Suicídio de idosos sob a perspectiva de gênero. Ciência \& Saúde Coletiva, 17(8), 1983-1992. doi: 10.1590/ S1413-81232012000800009

Minayo, M. C. S. (2002). Hermenêutica-dialética como caminho do pensamento social. In M. C. S. Minayo, \& S. F. Deslandes (Orgs), Caminhos do pensamento: epistemologia e método (pp. 83-108). Rio de Janeiro: Editora Fiocruz.

Minayo, M. C., \& Cavalcante, F. G. (2010). Suicide in elderly people: a literature review. Revista de Saúde Pública, 44, 750-757. doi: 10.1590/ S0034-89102010000400020

Minayo, M. C. S., Cavalcante, F. G., Figueiredo, A. E. B., \& Mangas, R. M. (2013). Estudo sobre tentativas de suicídio em idosos sob a perspectiva da saúde pública. Rio de Janeiro: Centro Latino-Americano de Estudos de Violência e Saúde (CLAVES/Fiocruz).

Ministério da Saúde. (2006). Estratégia nacional de prevenção do suicídio; prevenção de suicídio: manual dirigido a profissionais das equipes de saúde mental. Brasília. Recuperado de http://bvsms. saude.gov.br/bvs/publicacoes/manual_editoracao.pdf

Mitty, E., \& Flores, S. (2008). Suicide in late life. Geriatric Nursing, 29(3),160-165. doi: 10.1007/s11920-011-0193-3

Oliveira, A. A. A., \& Justo, J. S. (2010). Expressões do tédio na contemporaneidade: uma análise do romance "Encontro Marcado", de Fernando Sabino. Revista de Psicologia da UNESP, 9(1), 40-52.

Parente, A. C. M., Soares, R. B., Araújo, A. R. F., Cavalcante, I. S., \& Monteiro, F.S. (2007). Caracterização dos casos de suicídio em uma capital do nordeste brasileiro. Revista Brasileira de Enfermagem, 60(4), 377-381. doi: 10.1590/S0034-71672007000400003

Peixeiro, M. H. (2010). Paralisia do tempo e vazio no envelhecimento. Recuperado de http://wwwrevistas.pucsp.br/index.php/ kairos/ article/download/2674/1719 
Tédio enquanto circunstância potencializadora de tentativas de suicídio na velhice

Sher, L. (2006). Alcoholism and suicidal behavior: a clinical overview. Acta Psychiatric Scandinavica, 113, 13-22. doi: 10.1111/j.1600$-0447.2005 .00643 . x$

Svendsen, L. (2006). Filosofia do tédio. Rio de Janeiro: Jorge Zahar Editor.

Toohey P. (2012). Boderom: a lively history. Londres: New Haven Press.
Watt, J. D., \& Vodanovich, S. J. (1999). Boredom Proneness and Psychosocial Development. Journal of Psychology, 133(1), 149-155. doi:10.1080/00223989909599743

Werlang, B. S. G., Macedo, M. M. K., \& Asnis, N. (2005). Entrevistas retrospectivas: autópsia psicológica. In M. M. K. Macedo \& L. K. Carrasco (Orgs.), (Com)textos de entrevista: olhares diversos sobre a interação humana (pp. 45-54). São Paulo: Casa do Psicólogo.

Maria Cecilia de Souza Minayo, Doutora em Saúde Pública pela Escola Nacional de Saúde Pública (ENSP), Fundação Oswaldo

Cruz (FIOCRUZ), é pesquisadora titular da Fundação Oswaldo

Cruz (FIOCRUZ). Endereço para correspondência: Praia do Flamengo, 194/601 - CEP: 22210-030 - Rio de Janeiro, RJ. Telefone: (21) 3882-9153. E-mail: cecília@claves.fiocruz.br; maminayo@terra.com.br

Selena Mesquita de Oliveira Teixeira, Mestre em Psicologia pela Universidade de Fortaleza (UNIFOR), é Doutoranda em Psicologia pela Universidade de Fortaleza (UNIFOR), Bolsista pela Fundação Cearense de Apoio ao Desenvolvimento Científico e Tecnológico (FUNCAP), Professora do curso de Psicologia da

Faculdade Integral Diferencial (FACID) Devry Brasil e Pesquisadora do LEPES - Laboratório de Estudos sobre Processos de Exclusão Social (UNIFOR). E-mail: selenateixeira@hotmail.com

José Clerton de Oliveira Martins, Doutor em Psicologia pela Universidad de Barcelona - UB/Espanha, Pós-doutorado em Estudos do Ócio e Desenvolvimento Humano pela Universidad de Deusto-UD/Espanha, é Professor Titular do Programa de Pós-graduação em Psicologia da Universidade de Fortaleza (UNIFOR).E-mail: jclertonmartins@gmail.com 